\title{
A 6-Month-Old Boy with Reddish, Scaly Skin: Netherton Syndrome
}

\author{
(1) Fatma Derya Bulut1, (1) Deniz Kör1, (1) Berna Şeker Yılmaz1, () Mustafa Yılmaz2, (1) Derya Ufuk \\ Altıntaş2, ๑ Serdar Ceylaner3, ๑ Sebile Kılavuz', ๑ Neslihan Önenli Mungan1 \\ ${ }^{1}$ Çukurova University Faculty of Medicine, Department of Pediatrics, Division of Pediatric Metabolism and Nutrition, Adana, Turkey \\ 2 Çukurova University Faculty of Medicine, Department of Pediatrics, Division of Pediatric Allergy and Immunology, Adana, Turkey \\ 3Intergen Genetic Laboratory, Ankara, Turkey
}

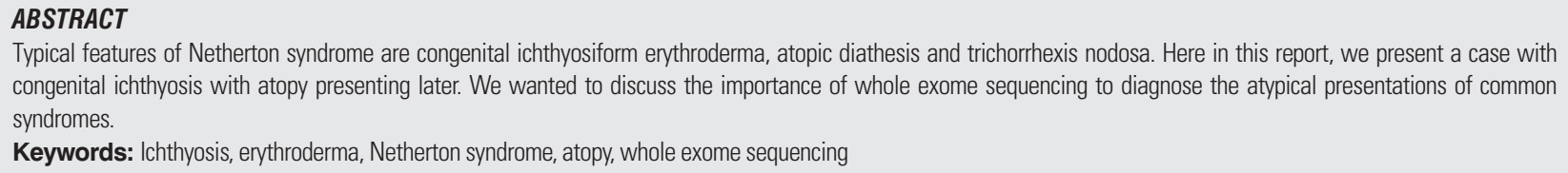

\section{Introduction}

Netherton syndrome (OMIM \#256500) is an autosomal recessively inherited syndrome, first described by Netherton (1). Netherton syndrome is caused by homozygous or compound heterozygous mutations in the SPINK5 gene, which encodes the serine protease inhibitor LEKTI (lymphoepithelial Kazal-type-related inhibitor), on chromosome 5 q32 (2). Clinical features are congenital ichthyosiform erythroderma, atopic diathesis and specific bamboo hair appearance (3). Less than a hundred cases have been reported so far. However, atypical cases make the diagnosis difficult. We present a case of Netherton syndrome with congenital ichthyosis with atopy presenting later.

\section{Case Report}

A six-month-old boy was admitted to our hospital due to dry, reddish, scaly skin and failure to thrive. He was born by caesarean section at 38 weeks gestational age to a 26-yearold, G1P1, healthy woman. He weighed 2900 gr (appropriate for gestational age). He had respiratory distress soon after birth, was diagnosed with neonatal pneumonia and stayed at the neonatal intensive care unit for 15 days. His skin findings started when he was 1 week old and became worse in time, although the family applied some skin ointments and zinc suspensions. He was breastfed supplemented with infant formula. He had loose stools but did not have chronic diarrhea. The patient's parents were first degree cousins, other than this, his family history was unremarkable.

On physical examination, weight, height and head circumference were $3500 \mathrm{gr}, 52 \mathrm{~cm}$ and $39 \mathrm{~cm}$ respectively (all below the third percentile for his age). His general appearance was well, he had normal motor and mental development. He had generalized, scaly erythroderma (Figure 1, informed consent was taken from patient's legal guardians). On auscultation, he had normal respiratory sounds, normal heart rate and no murmur. He had mild

\section{Address for Correspondence}

Fatma Derya Bulut MD, Çukurova University Faculty of Medicine, Department of Pediatrics, Division of Pediatric Metabolism and Nutrition, Adana, Turkey Phone: +90 5327432718 E-mail: dozduran@cu.edu.tr ORCID ID: orcid.org/0000-0003-0529-2404

Received: 24.09.2017 Accepted: 25.11.2017

(๑) Copyright 2018 by Ege University Faculty of Medicine, Department of Pediatrics and Ege Children's Foundation

The Journal of Pediatric Research, published by Galenos Publishing House. 


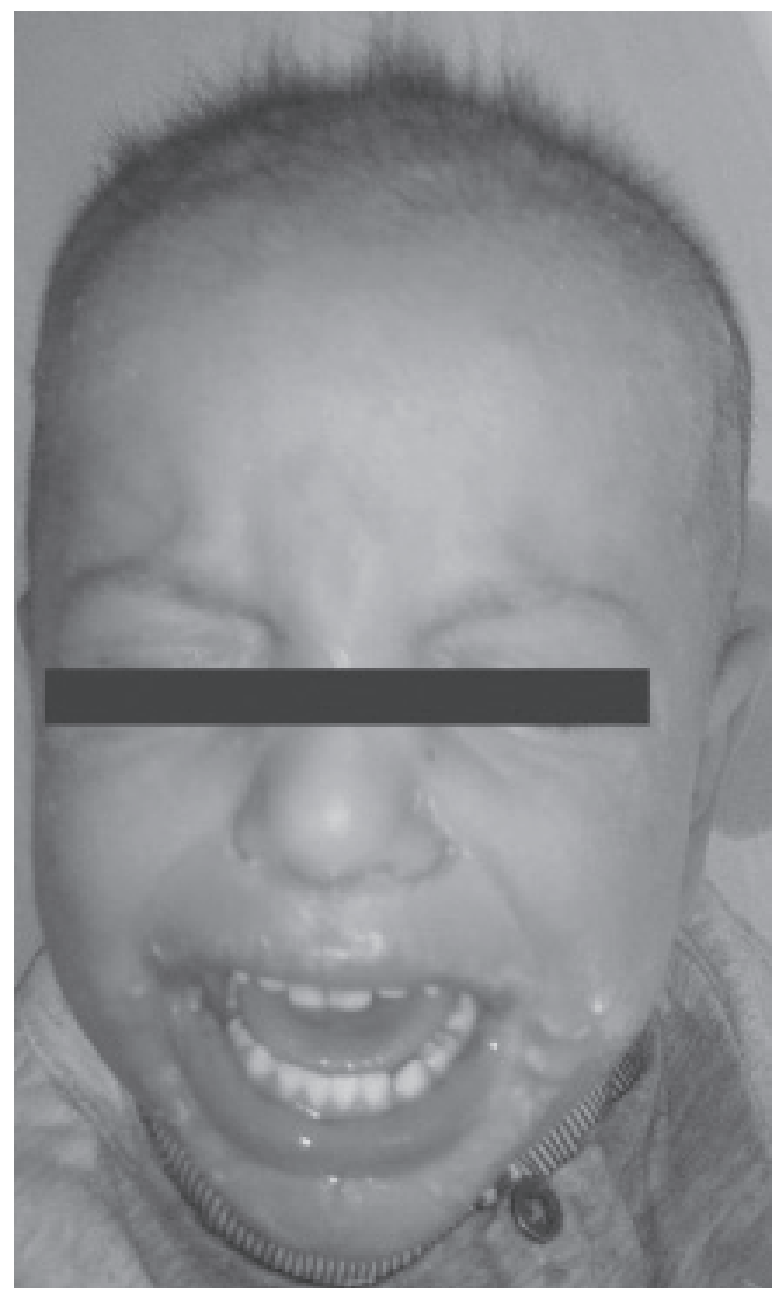

Figure 1. Scaly ichthyosiform erythroderma of patient's face, without apparent bamboo hair appearance

hepatosplenomegaly. He had no limb anomaly. He had sparse eyebrows and sparse scalp hair.

On laboratory investigation, the patient had mild anaemia (hemoglobin: $9.64 \mathrm{~g} / \mathrm{dL}$, hematocrit: $29.9 \%$ ), normal liver transaminases (aspartate aminotransferase: $26 \mathrm{IU} / \mathrm{L}$, alanine aminotransferase: $17 \mathrm{IU} / \mathrm{L}$ ) and hypoalbuminemia (albumin: $2.3 \mathrm{~g} / \mathrm{dL}$ ). Thyroid function tests, anti-tissue transglutaminase and anti-endomysial antibodies were within normal limits for age. Serum immunoglobulin E (lgE) level was $841 \mathrm{IU} /$ $\mathrm{mL}$ (normal: 10-180). Other Ig levels were within reference range for age (IgG: $1315 \mathrm{IU} / \mathrm{mL}$, IgA: $127 \mathrm{IU} / \mathrm{mL}$, IgM: $351 \mathrm{IU} /$ $\mathrm{mL}$ ). In order to investigate the underlying atopy, a skin prick test was done and revealed negative. The peripheral blood smear showed the prominence of eosinophilia labsolute eosinophil count: 12\%). Differential diagnoses for this infant were autosomal recessive lamellar ichthyosis and harlequin ichthyosis. For autosomal recessive congenital ichthyosis and harlequin ichthyosis, molecular analyses of TGM1, NIPAL4 and ABCA12 genes were all normal. Since he had mild hepatosplenomegaly along with the skin findings, Gaucher disease Type II was suspected but molecular analysis of the GBA gene was normal. For a definite diagnosis, a whole exome sequencing was performed and detected a known, disease causing homozygous mutation in SPINK5 gene [IVS2+5G $>$ T $(\mathrm{c} .81+5 \mathrm{G}>\mathrm{T})]$. The diagnosis was Netherton syndrome. Although the patient had a negative skin prick test, food specific IgE panel revealed that plasma levels of egg white specific IgE, milk specific $\lg E$ and wheat specific IgE were all high $(65.5,8.51$ and $38.7 \mathrm{kUA} / \mathrm{L}$ respectively). Milk, wheat and egg white were all eliminated from his diet and his skin condition improved in the course of time. Food challenge tests for milk, wheat and egg white were all positive and these three foods were permanently eliminated from the diet. Concurrently, microscopically, his hair exhibited the typical bamboo hair appearance gradually and erythroderma resolved with the restricted diet. Netherton syndrome (OMIM \#256500) is an autosomal recessive disorder, characterized by congenital ichthyosiform erythroderma, atopic diathesis and trichorrhexis nodosa (3). Rarely collodion babies are seen. The disorder is commonly confused with atopic dermatitis but does not respond to topical corticosteroid treatment (4). In the beginning, our patient was suspected of atopy but he had a negative skin prick test. Subsequently, food specific lgE panel and food challenge tests revealed the atopy. The false negative skin prick test was attributed to ichthyosis. Rarely, progressive and fatal hypernatremic dehydration may be seen in infants. In our patient, due to a coincidental neonatal pneumonia, our patient was well-hydrated in the neonatal intensive care unit and hypernatremic dehydration was not seen. His malnutrition, hypoalbuminemia and iron deficiency anaemia were attributed to enteropathy which is consistent with the syndrome (5). Diagnosis may be delayed beyond the neonatal period until the appearance of the pathognomonic bamboo hair anomaly which may also be recognized along the disease course (5). Under a light microscope, hair showing nodular trichorrhexis is diagnostic (the distal area of hair invaginates toward its proximal area). The histological findings of skin biopsy are frequently non-characteristic thinning of the granular layer and stratum corneum, psoriasiform hyperplasia and less common compact parakeratosis with large nuclei, subcorneum or intracorneum splitting, presence of clear cells in the upper epidermis or stratum corneum, dyskeratosis, dermal infiltrate with neutrophils and/or eosinophils and dilated blood vessels in the superficial dermis (6). On transmission electron microscopy, immature lamellar granules are observed between keratinocytes (7). Another non-invasive diagnostic method is molecular analysis of the SPINK5 gene, this provides a genetic counselling opportunity to the family. Treatment is symptomatic and requires prompt management of the neonatal complications such as fluid and electrolyte management, an elimination diet to prevent atopic dermatitis and long-term use of emollients and/or topical immunomodulators for amelioration of the skin disorder $(7,8)$. Some patients responded to ammonium lactate lotion, the per oral retinoid and psoralen plus ultraviolet $A$ therapy. The prognosis may be severe in neonates with life-threatening complications like recurrent dermal infections, fluid and 
electrolyte abnormalities and postnatal lethality is high. The skin manifestations and hair anomalies persist throughout life, but the disease usually improves with age and most patients begin to thrive during the second year of life $(6,7)$.

\section{Discussion}

More than a hundred conditions are described relating to ichthyosis. It is important to make the specific diagnosis by detecting features other than skin findings in order to establish proper treatment, predict the prognosis and also provide genetic counselling for the family. Molecular studies can be helpful in making an accurate diagnosis and are also non-invasive.

\section{Ethics}

Informed Consent: Informed consent was taken from patient's legal guardians.

Peer-review: External and internal peer-reviewed.

\section{Authorship Contributions}

Surgical and Medical Practices: F.D.B., N.Ö.M., Concept: F.D.B., N.Ö.M., Design: F.D.B., M.Y., D.U.A., N.Ö.M., Data Collection and Processing: F.D.B., Analysis and Interpretation: S.C., Literature Search: S.K., D.K., B.Ş.Y., Writing: F.D.B., S.K., D.K., B.S.Y., M.Y., D.U.A., S.C., N.Ö.M.

Conflict of Interest: There are no conflicts of interest.

Financial Disclosure: There is no financial support to disclose.

\section{References}

1. Netherton EW. A unique case of trichorrhexis nodosa: 'bamboo hairs'. Arch Derm 1958;78:483-7.

2. Chavanas S, Garner C, Bodemer C, et al. Localization of the Netherton syndrome gene to chromosome $5 q 32$, by linkage analysis and homozygosity mapping. Am J Hum Genet 2000;66:914-21

3. Bitoun $E$, Chavanas $S$, Irvine $A D$, et al. Netherton syndrome: disease expression and spectrum of SPINK5 mutations in 21 families. J Invest Derm 2002;118:352-61.

4. Smith DL, Smith JG, Wong SW, deShazo RD. Netherton's syndrome: a syndrome of elevated $\operatorname{lgE}$ and characteristic skin and hair findings. J Allergy Clin Immun 1995;95:116-23.

5. Fartasch M, Williams ML, Elias PM. Altered lamellar body secretion and stratum corneum membrane structure in Netherton syndrome: differentiation from other infantile erythrodermas and pathogenic implications. Arch Derm 1999; 135:823-32.

6. Leclerc-Mercier S, Bodemer C, Furio L, et al. Skin Biopsy in Netherton Syndrome: A Histological Review of a Large Series and New Findings. Am J Dermatopathol 2016;38:8391.

7. Tiryakioğlu NO, Önal Z, Saygili SK, Önal H, Ersoy Tunali $\mathrm{N}$. Treatment of ichthyosis and hypernatremia in a patient with Netherton syndrome with a SPINK5 c.153delT mutation using kallikrein inhibiting ointment. Int J Dermatol 2017;56:106-8

8. Yoneda K. Inherited ichthyosis: Syndromic forms. J Dermatol 2016;43:252-63 